\title{
Assessment of the orifice diameter by a multigated pulsed Doppler system in children with congenital semilunar valve stenosis
}

\author{
SIMON DE KNECHT, * JEROEN C W HOPMAN, * OTTO DANIËLS,* \\ GERARD B A STOELINGA,* ROBERT S RENEMAN, $\dagger$ ARNOLD P G HOEKS $\ddagger$ \\ From the ${ }^{\star}$ Paediatric University Clinic, Department of Pediatric Cardiology, University of Nijmegen; and \\ $\dagger$ Departments of Physiology and $\ddagger$ Biophysics, University of Limburg, Maastricht, The Netherlands
}

SUMMARY This study investigated whether the jet diameter measured by a multigated pulsed Doppler system could be used to assess the severity of valve disease in children with pulmonary $(n=11)$ or aortic $(n=4)$ valve stenosis. The results obtained were compared with those obtained at cineangiography and at operation. Multigated pulsed Doppler examination of a stenosed valte showed a region of relatively high velocities in the velocity profile (jet flow). There was good agreement between the diameter of the disturbed region on the Doppler echocardiogram and the diameter of the jet on the lateral angiocardiogram. In severe valve stenosis the agreement between the valve diameters measured by multigated pulsed Doppler and at operation was also good. In less severe valve stenosis Doppler measurements systematically underestimated the valve diameter at operation. It is likely that the functional opening of a semilunar valve is a more relevant estimate of the degree of stenosis than the anatomical measurement of the orifice.

The findings of this study indicate that multigated pulsed Doppler systems are useful in the noninvasive diagnosis of stenotic valve disease.

The severity of valve stenosis is usually assessed by the pressure gradient across the valve ${ }^{12}$ or from the orifice area (calculated by the Gorlin formula ${ }^{3}$ ). The orifice area can also be derived from the width of a jet of contrast. ${ }^{4}$ This angiocardiographic orifice area accorded with the haemodynamically calculated orifice area, when the area of the stenosis was assumed to be circular. ${ }^{4}$ In eight out of nine patients the valve orifice calculated from the angiocardiographic jet diameter was smaller than the diameter measured during operation. ${ }^{5}$

The introduction of echocardiography, especially cross sectional and Doppler techniques, has improved the potential for the non-invasive prediction of the severity of valve stenosis. ${ }^{6}$ Pulsed and continuous wave Doppler systems allow the gradient across a stenotic valve to be calculated from the Bernoulli equation. ${ }^{7-9}$ But this approach is restricted

Requests for reprints to Dr Simon de Knecht, Department of Paediatric Cardiology, University Hospital Nijmegen, Geert Grooteplein Zuid 20, 6500 HB Nijmegen, The Netherlands.

Accepted for publication 6 February 1989 by the dependence of the pressure gradient on cardiac output. Also single gated pulsed Doppler systems cannot accurately detect high blood flow velocities. So single gated pulsed Doppler is reliable only in mild pulmonary valve stenosis. ${ }^{10}$

Johnson et al used a single gated pulsed Doppler device to detect the jet in aortic valve stenosis. ${ }^{11}$ They measured the diameter of the jet by assessing the width of a region of flow disturbance distal to the stenosis. But this technique was accurate only when stenosis was severe. Recently, Veyrat et al introduced a single gated pulsed Doppler mapping technique to assess the severity of aortic valve stenosis in adults. ${ }^{12}$ The method reliably diagnosed less severe aortic valve stenosis, but it was time consuming.

Multigated pulsed Doppler systems allow the online recording of series of velocity profiles at discrete time intervals during a cardiac cycle. ${ }^{13-15}$ Under normal circumstances the systolic velocity profiles in the pulmonary artery and ascending aorta are likely to be nearly flat, but valve stenosis produces a region of relative high flow velocities (a jet).

We have assessed the accuracy of a multigated pulsed Doppler system used to measure orifice size 
non-invasively. The multigated method is less dependent on cardiac output than the single gated method.

\section{Patients and methods}

\section{PATIENTS}

For 28 months all children with pulmonary valve or aortic valve stenosis undergoing catheterisation and subsequent cardiac surgery were admitted to the study if satisfactory cross sectional and Doppler echocardiograms were obtained with a $5 \mathrm{MHz}$ system and it was possible to perform a multigated pulsed Doppler investigation. The investigation was part of the routine examination before heart catheterisation and operation.

Eleven children had isolated pulmonary valve stenosis. The age at catheterisation ranged from 14 days to 3 years 8 months except for one patient with Noonan's syndrome, ${ }^{16}$ who was 11 years 8 months. The second group consisted of four children with aortic valve stenosis, aged from 13 days to 1 year 2 months at catheterisation.

In those with pulmonary stenosis the delay between catheterisation and operation was about two months (range 13 days to 4 months 3 weeks). In two children (cases 1 and 5, table 1) the delay was 23 and 20 months. In all those with pulmonary stenosis all multigated pulsed Doppler examinations were per- formed a few days before operation, under sedation if necessary.

The mean interval between the multigated pulsed Doppler examination and catheterisation or operation was 10 days (range 1-30 days) in those with aortic valve stenosis.

\section{CATHETERISATION STUDIES}

All children were investigated by catheterisation except for one patient with pulmonary valve stenosis. She had an operation on the basis of echocardiographic and Doppler investigations alone.

Catheterisation was performed under general anaesthesia with artificial ventilation. Pressures were measured under steady state conditions; when it was possible to pass the stenosis we measured the gradient across the stenosed valve.

The ratio of right (RV) to left ventricular systolic pressure (LV) was used to estimate the severity of the stenosis in patients with pulmonary valve stenosis (modification after Emmanouilides and Baylen ${ }^{1}$ ). To avoid the effects of infundibular stenosis we measured the pressure in the right ventricular outflow tract and not in the cavity. Severe pulmonary valve stenosis was defined as a $R V / L V$ ratio $\geqslant 1.00$ and a moderate stenosis as a $R V / L V$ ratio between 0.5 and $1 \cdot 00$.

When the left ventricle could not be reached at catheterisation we measured the systolic brachial

Table 1 Orifice diameters in pulmonary valve and aortic valve stenosis measured by multigated pulsed Doppler (MPD), cineangiocardiography, and at operation. The reference standards for age and height are derived from Schulz and Giordano. ${ }^{19}$

\begin{tabular}{|c|c|c|c|c|c|c|}
\hline \multirow[b]{3}{*}{$\begin{array}{l}\text { Patient } \\
\text { number }\end{array}$} & \multirow[b]{3}{*}{$\begin{array}{l}R V \mid L V \text { systolic } \\
\text { pressure ratio }\end{array}$} & \multicolumn{5}{|c|}{ Pulmonary valve stenosis } \\
\hline & & \multicolumn{3}{|l|}{ Before operation } & \multicolumn{2}{|l|}{ At operation } \\
\hline & & $\begin{array}{l}\text { MPD } \\
\text { diameter ( } \mathrm{mm})\end{array}$ & $\begin{array}{l}\text { Angio jet } \\
\text { diameter ( } \mathrm{mm} \text { ) }\end{array}$ & $\begin{array}{l}\text { Reference } \\
\text { diameter ( } \mathrm{mm})\end{array}$ & $\begin{array}{l}\text { Operation } \\
\text { diameter ( } \mathrm{mm} \text { ) }\end{array}$ & $\begin{array}{l}\text { Reference } \\
\text { diameter ( } \mathrm{mm})\end{array}$ \\
\hline \multirow[t]{3}{*}{$\begin{array}{r}1 \\
2 \\
3 \\
4 \\
5 \\
6 \\
7 \\
8 \\
9 \\
10 \\
11\end{array}$} & $\begin{array}{l}0.53 \\
0.57 \\
0.64 \\
0.69 \\
0.70 \\
0.70 \\
1.00 \\
1.14 \\
1.17 \\
1.60 \\
-\end{array}$ & $\begin{array}{l}4 \cdot 9 \\
6 \cdot 3 \\
4 \cdot 4 \\
7 \cdot 3 \\
-1 \\
3 \cdot 1 \\
5 \cdot 8 \\
5 \cdot 5 \\
4 \cdot 2 \\
4 \cdot 1 \\
7 \cdot 3\end{array}$ & $\begin{array}{l}4 \cdot 9 \\
5 \cdot 2 \\
3 \cdot 7 \\
6 \cdot 5 \\
7 \cdot 0 \\
3 \cdot 5 \\
5 \cdot 1 \\
5 \cdot 2 \\
\text { No jet } \\
3 \cdot 0 \\
-\end{array}$ & $\begin{array}{r}13 \cdot 7 \\
10 \cdot 4 \\
14 \cdot 3 \\
15 \cdot 7 \\
13 \cdot 2 \\
10 \cdot 1 \\
12 \cdot 6 \\
14 \cdot 1 \\
7 \cdot 2 \\
7 \cdot 3 \\
11 \cdot 0\end{array}$ & $\begin{array}{r}12 \\
11 \\
11 \\
12 \\
9 \\
6 \\
6 \\
5 \\
4 \\
3 \\
6\end{array}$ & $\begin{array}{r}14 \cdot 7 \\
10 \cdot 6 \\
14 \cdot 3 \\
16 \cdot 3 \\
14 \cdot 1 \\
10 \cdot 2 \\
12 \cdot 7 \\
14 \cdot 2 \\
8 \cdot 6 \\
9 \cdot 2 \\
11 \cdot 0\end{array}$ \\
\hline & & \multicolumn{5}{|c|}{ Aortic valve stenosis } \\
\hline & & \multicolumn{3}{|l|}{ Before operation } & \multicolumn{2}{|l|}{ At operation } \\
\hline $\begin{array}{l}\text { Patient } \\
\text { number }\end{array}$ & $\begin{array}{l}L V-A O \text { gradient } \\
\text { in mm } H_{g}\end{array}$ & $\begin{array}{l}\text { MPD } \\
\text { diameter ( } \mathrm{mm})\end{array}$ & $\begin{array}{l}\text { Angio jet } \\
\text { diameter ( } \mathrm{mm} \text { ) }\end{array}$ & $\begin{array}{l}\text { Reference } \\
\text { diameter ( } \mathrm{mm})\end{array}$ & $\begin{array}{l}\text { Operation } \\
\text { diameter ( } \mathrm{mm} \text { ) }\end{array}$ & $\begin{array}{l}\text { Reference } \\
\text { diameter }(\mathrm{mm})\end{array}$ \\
\hline $\begin{array}{l}12 \\
13 \\
14 \\
15\end{array}$ & $\begin{array}{l}50 \\
75 \\
45 \\
95\end{array}$ & $\begin{array}{l}3.8 \\
3.9 \\
3.8 \\
3.6\end{array}$ & $\begin{array}{l}3.8 \\
3.7 \\
3.8 \\
3.4\end{array}$ & $\begin{array}{l}6 \cdot 8 \\
8 \cdot 7 \\
7 \cdot 3 \\
8 \cdot 3\end{array}$ & $\begin{array}{l}4 \\
3 \\
3 \\
3\end{array}$ & $\begin{array}{l}6 \cdot 8 \\
8 \cdot 7 \\
8 \cdot 3 \\
8 \cdot 3\end{array}$ \\
\hline
\end{tabular}

$R V$, right ventricle; $L V$, left ventricle; $A O$, aorta. 


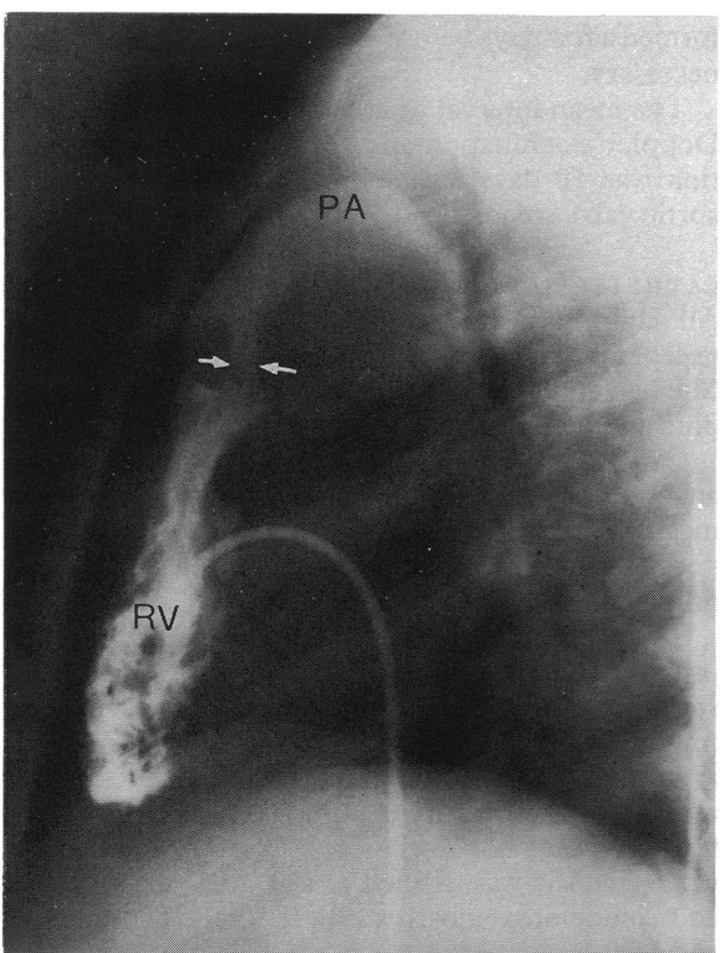

Fig 1 Lateral cineangiocardiographic view of the jet in pulmonary valve stenosis after contrast injection into the right ventricle. The diameter of the jet is measured just downstriam from the stenotic valve. The site of measurement is indicated with two arrows. $R V$, right ventricle;

$P A$, pulmonary artery.

artery pressure by an appropriate cuff, using a Dynamap blood pressure measuring system. This systemic arterial pressure was then used to assess the RV/LV ratio.

In infants aortic valve stenosis was regarded as severe when the peak systolic gradient across the valve was $\geqslant 50 \mathrm{~mm} \mathrm{Hg}$. In critical aortic valve stenosis, however, the pressure in the left ventricle and the gradient across the valve may be lower because left ventricular function is impaired; this will lead to an underestimation of the severity of the disease.

\section{CINEANGIOCARDIOGRAPHY}

Cineangiocardiography was performed during catheterisation to visualise the jet stream. A lateral view was used in those with pulmonary valve stenosis and a left anterior oblique view in those with aortic valve stenosis. The contrast medium was Angiografin $65 \%$ (meglumine-amidotrizoate) in a dose of $0.5-2 \mathrm{mg} / \mathrm{kg}$ body weight. The contrast medium was injected into the cavity of the ventricle with a catheter dependent flow rate (NIH 5-7 F). The cine frame rate was $75 / \mathrm{s}$ (fig 1 ).

From each film we selected a frame showing a well defined opacified jet and we measured the diameter of the jet stream. This procedure was performed three times with an interval of at least one day between the measurements. The site of measurement was just downstream of the stenotic valve. In most cases the jet flow was detected in early systole of the first or second heart beat after contrast injection. We used the diameter of the image of the catheter in the right ventricular outflow tract as a reference to calculate the real jet diameters. We took the mean of a series of three measurements as the diagnostic value.

MULTIGATED PULSED DOPPLER MEASUREMENTS We used a $5 \mathrm{MHz}$ multigated pulsed Doppler system with 64 adjacent sample volumes over a distance of $38.4 \mathrm{~mm}$ (one sample volume $=0.6 \mathrm{~mm}$ in length). To visualise the site of investigation, we connected the multigated pulsed Doppler system to an ATL mark $\mathrm{V}$ real time echo-scanner. The site of sampling across the vessel was selected by moving the $M$ line direction and adapting the delay indicating the depth of the sample range along the $M$ line just as in the single gated pulsed Doppler system.

Measurements were made with child lying on its left side. To visualise the pulmonary artery or the ascending aorta in a long axis view, we placed the transducer in the first or second left intercostal space in patients with pulmonary valve stenosis and in the third or fourth intercostal space in patients with aortic stenosis. If necessary the patients were sedated with an intramuscular injection of promethazine $(0.5$ $\mathrm{mg} / \mathrm{kg})$, chlorpromazine $(0.5 \mathrm{mg} / \mathrm{kg})$, and pethidine $(1 \mathrm{mg} / \mathbf{k g})$.

The flow velocity profiles of the orifice were recorded with the $M$ line positioned just downstream from the stenotic valve. ${ }^{17}{ }^{18}$ The angle of the $M$ line to the axis of the pulmonary artery was measured on the sector scan. To calculate the jet diameter we assumed that the flow direction corresponded with the axis of the pulmonary artery. To obtain a cross sectional profile we chose an angle of about $80^{\circ}$; at $90^{\circ}$ the Doppler signal becomes impaired. Narrowing of the valve orifice caused a region of high velocities in the profile. The diameter of this region in systole was assumed to represent the flow diameter of the orifice. Aliasing was seen if the jet flow exceeded the velocity limits of the pulsed mode. When this happened we increased the angle of interrogation. An observation close to $90^{\circ}$ with the jet will affect the accuracy with which the jet diameter can be established since the velocities, corrected for the estimated angle, are compared with a threshold. With a pulse repetition frequency of $7.8 \mathrm{KHz}$, velocities of up to $60 \mathrm{~cm} / \mathrm{s}$ can 


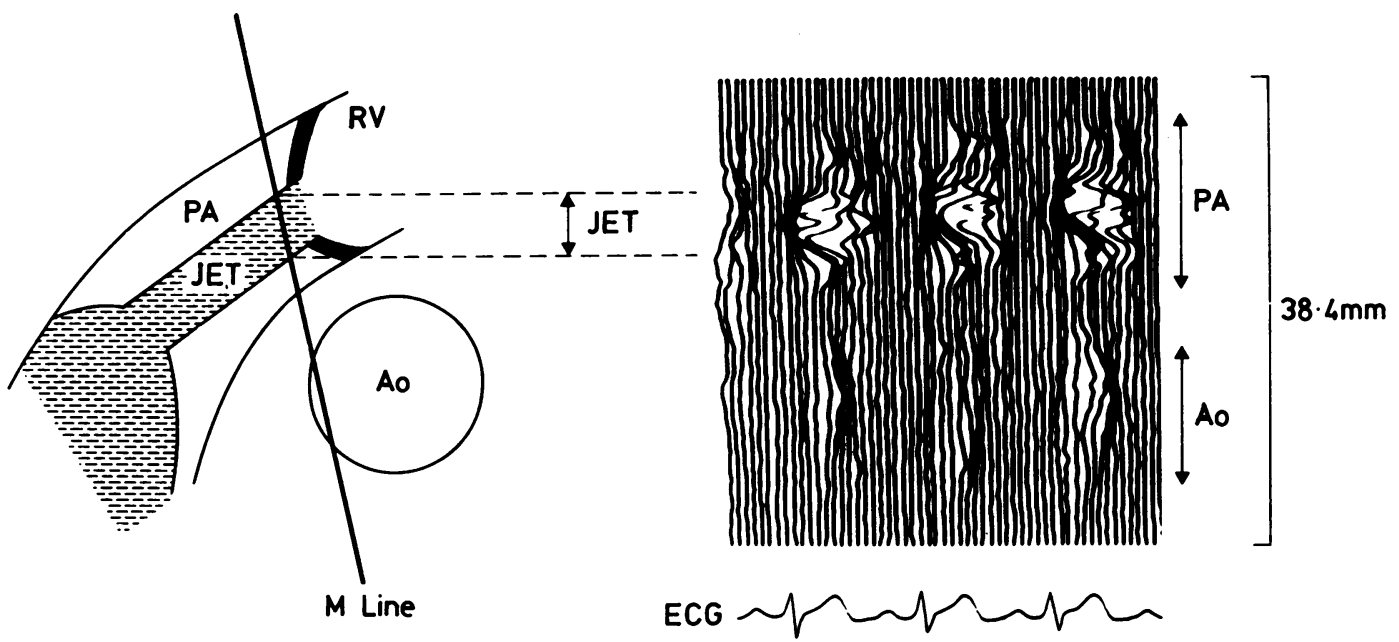

Fig 2 Example of a pulmonary valve stenosis investigated with multigated pulsed Doppler. The site of measurement $(M$ line) is indicated. There are three measurable orifice flow profiles in the pulmonary artery $(P A)$. In systole in the first flow profile the diameter of the ostium flow is indicated ("JET"). It runs from the beginning of the first fast deflection till the end of this deflection. The jet diameter is related to the total length of the 64 sample gates (38.4 mm) and corrected for the angle between the flow direction and $M$ line. There are vague aortic (Ao) flow patterns below the pulmonary artery flow profiles. The electrocardiogram is shown as a time scale.

be estimated at $0^{\circ}$, up to $3.5 \mathrm{~m} / \mathrm{s}$ at $80^{\circ}$, and up to $7 \cdot 0$ $\mathrm{m} / \mathrm{s}$ at $85^{\circ}$. Deviations from the real jet direction (for instance $90^{\circ}$ ) and assumed jet direction (for instance $70^{\circ}$ ) are not critical because a deviation of $20^{\circ}$ gives rise to a maximum error of $12 \%$. The number of contributing gates $(0.6 \mathrm{~mm}$ each) gave the diameter of the jet flow, which was corrected for the estimated angle of interrogation (fig 2). A series of frames of velocity profiles was stored and only the largest and most typical jet flow patterns were chosen because the smaller disturbances will have been measured obliquely. Measurements were repeated three times and the mean of these measurements was used for further analysis.

\section{MEASUREMENTS DURING OPERATION}

During operation the diameter of the pulmonary valve orifice was measured with a circular probe before valvotomy or valvectomy. The probe that just fitted the valve without stretching it was regarded as the size. To avoid accidental rupture of stenosed aortic valves we measured the length of the slit of the collapsed valve, which we assumed to be half the internal circumference of the orifice. This approach was necessary because the clinical consequences of aortic valve regurgitation are severe. These calculated measurements were rounded down to probe values. In one patient (case 12) the diameter was measured at necropsy.
We used the age and height dependent internal circumference reference values ${ }^{19}$ to calculate the valve orifice.

$\mathrm{S}$ de $\mathrm{K}$ measured the width of the jet by the multigated pulsed Doppler system and by angiocardiography. The surgeon was not informed of the outcome of the non-invasive measurements.

\section{STATISTICAL ANALYSIS}

The mean (2 SD) of paired differences was calculated to compare the results of multigated pulsed Doppler and cineangiocardiography. To compare the results of multigated pulsed Doppler and operation we calculated the mean ( $2 \mathrm{SD}$ ) for only the severe stenoses. All the results are presented (figs 3 and 4) with limits of agreement according to Bland and Altman ${ }^{20}$ and Gardner and Altman. ${ }^{21}$

\section{Results}

The $1 \mathrm{SD}$ of the mean of each series of three measurements ranged from 0.05 to $0.44 \mathrm{~mm}$ at angiocardiography and from 0.15 to $0.83 \mathrm{~mm}$ in the multigated pulsed Doppler measurements (one sample gate measures $0.6 \mathrm{~mm}$ ).

Table 1 lists the results. In patient 5 the multigated pulsed Doppler investigation was impossible because the child would not stay still. Patients 4 and 9 had 
Noonan's syndrome and in one of them no jet was detected. One patient (case 11) had cardiac operation without catheterisation; the reference diameter at operation suggested severe pulmonary stenosis (orifice area $<30 \%$ of normal (table 1 ). The valves were tricuspid (shape unknown in patient 6) in those with pulmonary stenosis and bicuspid in those with aortic stenosis.

Table 2 shows the mean ( 1 SD) of the paired differences of the different methods of investigation. There was strong agreement between the jet diameters assessed by the multigated pulsed Doppler system and angiocardiography. Figure 3 shows the combined results for the groups with pulmonary and aortic valve stenosis. The paired difference between the diameters measured by multigated pulsed Doppler and angiocardiography were compared with the mean diameter calculated from multigated pulsed Doppler and angiographic findings.

Figure 4 shows a comparison of the paired differences between the diameters assessed by multigated pulsed Doppler and at operation and the mean diameter derived from the findings at multigated pulsed Doppler and operation. The mean and 2 SD are calculated only for the severe pulmonary and aortic valve stenoses. The values of moderate pulmonary valve stenosis were outside these limits of agreement (2 SD), but agreement between the methods was good in patients with severe stenosis. The multigated pulsed Doppler method underestimated the diameter of moderately stenosed valves measured at operation, but only to the same extent as cineangiocardiography did.

\section{Discussion}

We found that, whatever the degree of stenosis, the jet diameter measured on the angiocardiogram corresponds well with the diameter measured by multigated pulsed Doppler. The diameter assessed from the width of the jets correlated well with the diameter measured at operation when pulmonary or aortic valve stenosis was severe. When the stenosis was less

Table 2 Comparison of diameters

(a) Diameters in all pulmonary and aortic valve stenoses

\begin{tabular}{lccc} 
Variable & No & Mean $(\mathrm{mm})$ & $1 S D$ \\
\hline Multigated minus angio & 12 & 0.40 & 0.46 \\
Multigated minus operation & 15 & -1.44 & 2.96 \\
Angio minus operation & 13 & -2.25 & 3.08 \\
& \multicolumn{4}{c}{} \\
(b) Diameters in severe pulmonary & and aortic valve stenoses \\
Variable & No & Mean (mm) & $1 S D$ \\
Multigated minus angio & 7 & 0.38 & 0.39 \\
Multigated minus operation & 9 & 0.57 & 0.53 \\
Angio minus operation & 7 & 0.13 & 0.57 \\
\hline
\end{tabular}

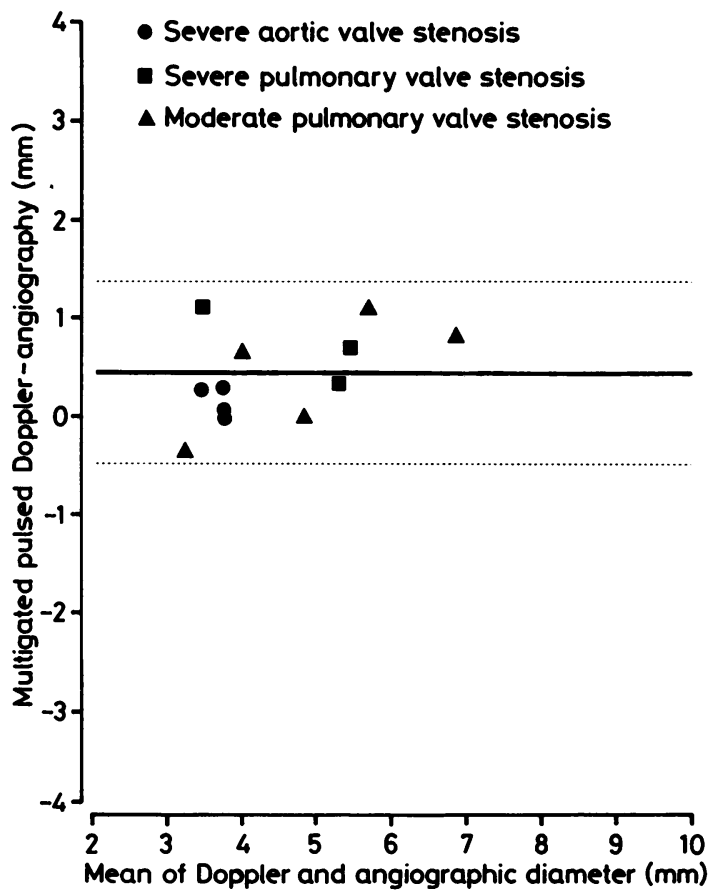

Fig 3 Patients with pulmonary or aortic valve stenosis. Differences between the diameters assessed with the multigated pulsed Doppler system and at cineangiocardiography are shown as a function of the mean diameters calculated from the findings with both methods. The mean (solid line) and $\pm 2 S D$ (dotted lines) are indicated.

severe, however, the diameter from the jet systematically underestimated the diameter measured at operation.

Multigated pulsed Doppler and angiography both measure functional diameter. With multigated pulsed Doppler systems a local disturbance in the flow profile can be visualised, and on the angiogram a region of fast filling contrast is seen. With multigated pulsed Doppler systems the frontal-dorsal diameter is assessed. The lateral projection at cineangiocardiography also estimates the frontal-dorsal diameter. In aortic valve stenosis a left oblique view is used, with nearly the same diameter in cross section as in

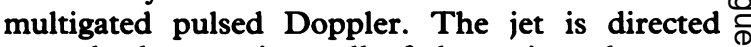
towards the anterior wall of the main pulmonary artery (fig 1). The multigated pulsed Doppler 0 measurements are performed at an angle of $O$ interrogation close to $90^{\circ}$. Underestimation of the

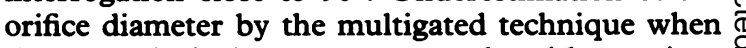
the stenosis is less severe accords with previous observations. ${ }^{52}$ Compression of the jet by areas of recirculation $^{23}$ is not likely to be responsible for the 


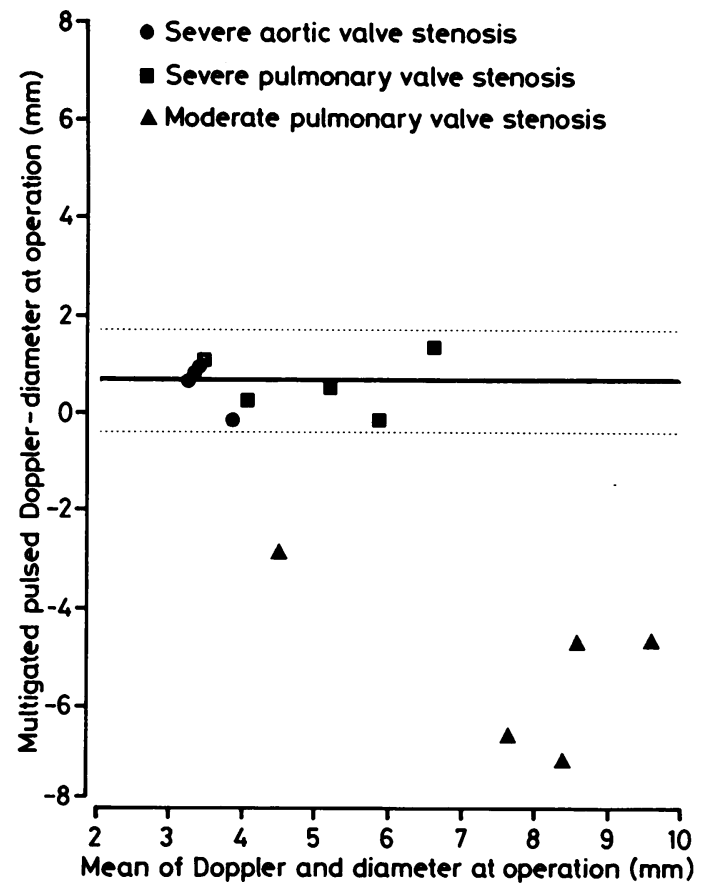

Fig 4 Patients with pulmonary or aortic valve stenosis. Differences between the diameters assessed with the multigated pulsed Doppler system and at operation are shown as a function of the mean diameters calculated from the findings with both methods. The mean (solid line) and $\pm 2 S D$ (dotted lines) of the severe pulmonary and aortic valve stenosis are indicated.

underestimation of the diameter. ${ }^{24}$ The most likely explanation for the discrepancy is the difference between functional opening and the anatomical orifice assessed at operation. Under normal circumstances and in slight to moderate valve diseases maximum valve opening is not needed for adequate outflow at rest. The probe method probably measures the largest possible circular aperture. In severe stenosis although the orifice reaches its largest possible diameter blood flow is obstructed. In this situation the diameter measured at operation is likely to be similar to the functional diameter because the orifice can only be passed by a probe with a diameter about equal to the maximum diameter of the valve orifice.

The idea that the valve diameter calculated from the width of the jet represents the functional diameter is supported by the fact that the jet diameter assessed by cineangiocardiography and the jet diameter calculated by the Gorlin equation are usually similar. ${ }^{45}$ Berman et al only reported on cineangiograms obtained in a lateral view. ${ }^{4}$ The assumption that the orifice is circular seems to be valid in more severe congenital pulmonary valve stenosis. ${ }^{25-28}$ When valve malformation is severe this assumption is not valid. These cases, however, can easily be diagnosed by cross sectional echocardiography. In one angiographic study the valve area was smaller than that calculated by the Gorlin equation. ${ }^{22}$ In this study, however, oxygen consumption (used to calculate cardiac output) was assumed rather than measured and this may introduce errors in the calculated haemodynamic area.

Nevertheless, in patients with moderate to severe aortic stenosis the diameter of the orifice measured by single gated pulsed Doppler flow mapping techniques resembled the diameter assessed haemodynamically. ${ }^{11}$ Although Veyrat et al warned that the orifice of the aortic valve may not be circular, ${ }^{12} 56 \%$ of the orifices were circular and only $6 \%$ were slits. These findings support the idea that functional assessment of the degree of stenosis is better than anatomical measurements.

With the new techniques of colour coded Doppler the jet is directly visible. Diameter measurements, however, depend on the adjustment of the colour imager. The combination of detection of jet direction by colour Doppler and measurement of the diameter by multigated pulsed Doppler seems promising.

In conclusion, a jet diameter that corresponds to that measured on the angiocardiogram can be measured non-invasively by multigated pulsed Doppler systems. This diameter probably represents the functional opening of the valve.

This investigation was supported by the Dutch Heart Foundation.

\section{References}

1 Emmanouilides GC, Baylen BG. Pulmonary stenosis. In: Adams FH, Emmanouilides GC, eds. Moss' heart disease in infants, children, and adolescents. Baltimore: Williams and Wilkins, 1983:234-62.

2 Friedman WF, Benson LN. Aortic stenosis. In: Adams FH, Emmanouilides GC, eds. Moss' heart disease in infants, children, and adolescents. Baltimore: Williams and Wilkins, 1983:171-88.

3 Gorlin R, Gorlin SG. Hydraulic formula for calculation of the area of the stenotic mitral valve, other cardiac valves, and central circulatory shunts. I. Am Heart J 1951;41:1-29.

4 Berman W Jr, Gross R, Marawala Z, Carlsson E. The measurement of pulmonic valve area by angiocardiographic and hemodynamic methods. Cardiovasc Radiol 1978;1:77-81.

5 Puyau FA, Hastings CP, Collins HA. Determination of orifice size in isolated pulmonary valvular stenosis. 
Comparison of three methods. Invest Radiol 1968;3: 367-71.

6 Daniëls O, de Knecht S, van Oort A, Busch HJ. The usefulness of echo-Doppler in pediatric cardiology. Acta Paediatr Scand [Suppl] 1986;329:108-10.

7 Holen J, Aaslid R, Landmark K, Simonsen S. Determination of pressure gradient in mitral stenosis with a noninvasive ultrasound Doppler technique. Acta Med Scand 1976;199:455-60.

8 Hatle L, Brubakk A, Tromsdal A, Angelsen B. Noninvasive assessment of pressure drop in mitral stenosis by Doppler ultrasound. Br Heart J 1978; 40:131-40.

9 Lima OC, Sahn DJ, Valdez-Cruz LM, et al. Noninvasive prediction of transvalvular pressure gradient in patients with pulmonary stenosis by quantitative two-dimensional echocardiographic Doppler studies. Circulation 1983;67:866-71.

10 Hatle L, Angelsen BA, Tromsdal A. Non-invasive assessment of aortic stenosis by Doppler ultrasound. Br Heart J 1980;43:284-92.

11 Johnson SL, Baker DW, Lute RA, Murray JA. Jet diameter in aortic stenosis, measured by Doppler echocardiography [Abstract]. Circulation 1973;47 and 48(suppl IV):126.

12 Veyrat C, Gourtchiglouian C, Dumora P, Abitbol G, Sainte Beuve D, Kalmanson D. A new non-invasive estimation of the stenotic aortic valve area by pulsed Doppler mapping. Br Heart J 1987;57:44-50.

13 Brandestini $M$. Topoflow-a digital full range Doppler velocity meter. IEEE Trans on Sonics Ultrasonics 1978;SU-25:287-93.

14 Hoeks APG. On the development of a multi-gate pulsed Doppler system, with serial data-processing. Maastricht, The Netherlands: University of Limburg, 1982. Thesis.

15 Reneman RS, van Merode T, Hick P, Hoeks APG. Cardiovascular applications of multi-gate pulsed Doppler systems. Ultrasound Med Biol 1986;12: 357-70.

16 Van der Hauwaert LG, Fryns JP, Dumoulin M, Logghe $N$. Cardiovascular malformations in
Turner's and Noonan's syndrome. $B r$ Heart $J$ 1978;40:500-9.

17 Daniëls O, de Knecht S, Hopman JCW, Hoeks APG Reneman RS. Applications of multigate pulsed Doppler systems in congenital heart disease. In: Spencer MP, ed. Cardiac Doppler diagnosis vol II. Dordrecht: Martinus Nijhoff, 1986:221-8.

18 de Knecht S, Daniëls O, Reneman RS. Non-invasive assessment of pulmonary valve stenosis with a multigate pulsed Doppler system. Br Heart $J$ 1983;50: 592-3.

19 Schulz DM, Giordano DA. Hearts of infants and children. Weights and measurements. Arch Pathol 1962;74:464-71.

20 Bland JM, Altman DG. Statistical methods for assessing agreement between two methods of clinical measurement. Lancet 1986;i:307-10.

21 Gardner MJ, Altman DG. Confidence intervals rather than P values: estimation rather than hypothesis testing. $\mathrm{Br}$ Med J 1986;292:746-50.

22 Rudhe U, Whitley JE, Herzenberg H. Mild pulmonary valvular stenosis studied functionally and anatomically. Acta Radiol 1962;57:161-71.

23 Caro CG, Pedly TJ, Schroter RC, Seed WA, eds. The mechanics of the circulation. Oxford: Oxford University Press, 1978:64.

24 Ask P, Loyd D, Wranne B. Regurgitant flow through heart valves: a hydraulic model applicable to ultrasound Doppler measurements. Med Biol Eng Comput 1986;24:643-6.

25 Brock $R$. The anatomy of congenital pulmonary stenosis. London: Cassell, 1957:56-7.

26 Anderson RH, Milo S, Zuberbuhler JR, Ho SY. Pulmonary and subpulmonary stenosis, an anatomic approach. In: Dunn JM, ed. Cardiac valve disease in children. New York, Elsevier, 1988:108.

27 Utley JR, Roe BB. Surgical considerations in obstruction of the right ventricular outflow tract. $J$ Thorac Cardiovasc Surg 1973;65:391-401.

28 Glenn WWL, Liebow AA, Lindskog GE. Thoracic and cardiovascular surgery with related pathology. 3rd ed. New York: Appleton-Century-Crofts, 1975:792. 